\title{
Reliability and Validity of a New Comprehensive Tool for Assessing Challenging Behaviors in Autism Spectrum Disorder
}

\author{
Johanna Inhyang Kim¹, Min-Sup Shin², Youngsun Lee ${ }^{3}$, Hyojung Lee ${ }^{4}$,

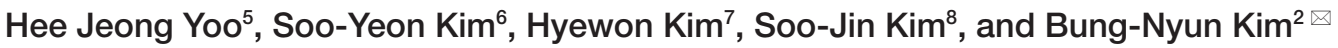 \\ ${ }^{1}$ Department of Public Health Medical Services, Seoul National University Bundang Hospital, Seongnam, Republic of Korea \\ ${ }^{2}$ Division of Child and Adolescent Psychiatry, Department of Psychiatry, Seoul National College of Medicine, Seoul, Republic of Korea \\ ${ }^{3}$ Department of Education, Inha University, Incheon, Republic of Korea \\ ${ }^{4}$ Department of Education, Dongguk University, Seoul, Republic of Korea \\ ${ }^{5}$ Department of Psychiatry, Seoul National University Bundang Hospital, Seongnam, Republic of Korea \\ ${ }^{6}$ Department of Psychiatry, Pusan National University Hospital, Busan, Republic of Korea \\ ${ }^{7}$ Department of Psychiatry, Seoul St. Mary's Hospital, Seoul, Republic of Korea \\ ${ }^{8}$ Seoultop Psychiatric Clinic, Seoul, Republic of Korea
}

Objective The purpose of this study was to examine the validity and reliability of the Korean Comprehensive Scale for the Assessment of Challenging Behavior in Developmental Disorders (K-CSCB).

Methods In total, the parents of 189 patients with autism spectrum disorder (ASD) and 168 controls completed the K-CSCB, the Behavior Problems Inventory (BPI) and Child Behavior Checklist (CBCL). The reliability and validity of the K-CSCB was investigated.

Results The K-CSCB was found to be a reliable instrument (Cronbach's $\alpha=0.97$ ). There was a significant difference between the ASD and control groups in all subscale scores. Scores on the K-CSCB subscales were significantly correlated with those on the BPI and CBCL. The diagnostic validity was $97.7 \%$, and the cut-off score with the highest sensitivity and specificity was 12.5 points.

Conclusion The K-CSCB is the first tool in Korean to assess problematic behavior in individuals with ASD, and this study shows that it is a valid and reliable instrument. We expect the K-CSCB to be widely used in clinical and research settings.

Psychiatry Investig 2018;15(1):54-61

Key Words Neurodevelopmental disorder, Psychometrics, Child and adolescent psychiatry.

\section{INTRODUCTION}

The number of individuals diagnosed with autism spectrum disorder (ASD) has been increasing, with estimates ranging from $0.07 \%$ to $2.64 \%{ }^{1-4}$ ASD is a developmental disorder characterized by impairment in social communication and restricted/repetitive behaviors. ${ }^{5}$ Although not included in the core symptoms of ASD, behavioral problems, including aggression, temper tantrums, non-compliance, and self-injurious behaviors, are burdensome to caregivers and commonly

Received: August 31, 2016 Revised: April 19, 2017

Accepted: April 26, 2017 Available online: November 16, 2017

$\triangle$ Correspondence: Bung-Nyun Kim, MD, PhD

Division of Child and Adolescent Psychiatry, Department of Psychiatry, Seoul National College of Medicine, 101 Daehak-ro, Jongno-gu, Seoul 03080, Republic of Korea

Tel: +82-2-2072-3647, Fax: +82-2-747-5774, E-mail: kbn1@snu.ac.kr

(a) This is an Open Access article distributed under the terms of the Creative Commons Attribution Non-Commercial License (http://creativecommons.org/licenses/bync/4.0) which permits unrestricted non-commercial use, distribution, and reproduction in any medium, provided the original work is properly cited. require intervention. ${ }^{6}$ Their presence can be a major impediment to activities, socialization, and other learning opportunities and can persist into adolescence and adulthood, affecting the long-term prognosis. ${ }^{7}$ A previous study reported that one-third of children aged 1.5 to 5.8 years showed problematic behaviors in the clinically significant range. ${ }^{8}$ Some studies have reported that over $90 \%$ of patients with ASD exhibit some form of challenging behavior. ${ }^{9}$

The need for the early identification and accurate assessment of these problem behaviors has led to the development of various measures designed to assess behavioral problems in ASD. The most widely used instruments include the Aberrant Behavior Checklist (ABC), ${ }^{10}$ Behavior Problems Inventory (BPI) ${ }^{11}$ Nisonger Child Behavior Rating Scales (NCBRF), ${ }^{12}$ Behavior Assessment System for Children (BASC), ${ }^{13}$ Home Situations Questionnaire-Pervasive Developmental Disorder version (HSQ-PDD) ${ }_{1}^{14}$ and Child Behavior Checklist (CBCL). ${ }^{15}$ These instruments vary in scope, length, targeted age and 
population. The ABC and NCBRF were initially designed to measure problem behaviors in individuals with intellectual disabilities, and the BASC and CBCL are tools that do not target a specific psychiatric diagnosis. Most tools mentioned are broad-band instruments and, as they encompass an extensive range of psychopathology, only a few items target problem behaviors. ${ }^{11}$ Moreover, evidence on the validity and reliability of these tools for individuals with ASD is limited. A recent review of the properties of tools that measure behavior problems in children with autism reported that, among 12 tools, there was evidence available for only 6 , and most showed mixed results. ${ }^{16}$ The CBCL and HSQ-PDD had the most robust measurement properties. However, the CBCL was developed to be used with typically developing children, and there was no evidence of its construct validity in children with ASD, whereas the HSQ-PDD was developed recently, and the developers are continuing to explore the most effective groupings of items. ${ }^{17}$

In South Korea, there has been increasing concern about managing the problem behaviors of patients with ASD, and the "Developmental Disabilities Assistance and Bill of Rights Act," enacted in November 2015, announced a plan to establish nationwide behavior development enhancement centers for the management of problem behavior in patients with developmental disorders. However, despite the increasing social awareness of the strong likelihood of problem behaviors in ASD, there is no instrument in South Korea with well-established validity and reliability that can accurately assess problematic behavior in individuals with ASD. With the exception of the CBCL and BASC, none of the pre-existing instruments has been standardized in Korean, ${ }^{18,19}$ and all were developed in Western countries, thus limiting their widespread use in South Korea.

Kim et al. (unpublished) developed a tool to assess challenging behavior in patients with ASD, the Korean Comprehensive Scale for the Assessment of Challenging Behavior in Developmental Disorders (K-CSCB). We pooled items from tools that were considered valid and reliable, collected information from caregivers and therapists about additional symptoms not included in the pooled items, and allowed a group of psychiatrists, educational professionals, clinical psychologists, and behavior therapists to determine face validity. The purpose of this study was to establish the reliability and validity of the K-CSCB. We recruited patients with ASD from both clinical and community settings to widen the generalizability of our study results to patients with ASD with various characteristics.

\section{METHODS}

\section{Participants}

Participants with ASD, aged 5-22 years, were recruited from hospitals and special education schools during the period of February 2016 to July 2016. The clinical group was recruited from the Seoul National University Children's Hospital and the Seoul National University Bundang Hospital. Diagnoses of ASD were confirmed by board-certified child and adolescent psychiatrists according to the Diagnostic and Statistical Manual of Mental Disorders, 4th edition (DSM-IV). Individuals with ASD who were receiving special education were recruited from six special education schools in Seoul and Incheon. Exclusion criteria were as follows: 1) schizophrenia or any other childhood-onset psychotic disorder, 2) mood disorders, 3) conduct disorder or oppositional defiant disorder, and 4) inability of the parents to understand or cooperate. The control group was defined as community-dwelling children who were free of any psychiatric diagnoses, and the exclusion criteria were the same as those applied to the ASD group, with the addition of an ASD diagnosis. We only included patients who completed more than $95 \%$ (84 out of 89 items) of the KCSCB.

After a detailed explanation of the study, written informed consent was obtained from the participants' legal guardians, and the study protocol was approved by the Institutional Review Board of Seoul National University Hospital (1406-016585).

\section{Assessment}

\section{The Korean Comprehensive Scale for assessment of Challenging Behavior in Developmental Disorders (K-CSCB)}

This scale was originally developed by Kim et al. (unpublished) to assess problematic behavior during the past 2 months in individuals with developmental disorders, particularly ASD. The items of this scale are listed in Supplementary Table 1 (in the online-only Data Supplement). It initially consisted of 89 items and six subcategories. There were 13 items addressing self-harm, 17 addressing aggressive behavior, 22 addressing stereotyped behavior, 13 addressing unresponsiveness and negativism, 12 addressing attention deficits and hyperactivity, and 12 addressing inappropriate words and behavior. It investigates various behaviors that may appear during the childhood, adolescence, and early adulthood of patients with developmental disorders and was designed to be completed by the primary caretaker of the patient (e.g., parent, teacher, or behavioral therapist). Each item assesses frequency on a five-point scale (from 0 to 4 , with 4 being the most 
frequent) and severity on a four-point scale (from 0 to 3 , with 3 being the most severe).

\section{Behavior Problems Inventory}

The Behavior Problems Inventory (BPI) is a 52-item narrowband behavior rating scale for behavior problems in individuals with developmental disorders. ${ }^{11}$ It assesses the severity and frequency of problem behaviors and includes 14 items related to self-injurious behaviors, 24 items related to stereotypic behaviors, and 11 items related to aggressive/destructive behaviors. The reliability and validity of the BPI have been well established, with a full-scale Cronbach's $\alpha$ of 0.83 , testretest reliability of 0.76 , inter-rater reliability of 0.92 , and fair criterion validity as assessed by diagnoses of pervasive developmental disorder (PDD) or stereotyped movement disorders.

\section{Child Behavior Checklist 1.5-5}

The Child Behavior Checklist (CBCL) $1.5-5$ is a 100 -item parent-report measure that is widely used to screen for problematic behaviors; however, this instrument does not target any specific psychiatric diagnosis. ${ }^{20}$ The CBCL $1.5-5$ is known to have good reliability and validity. ${ }^{20}$ The CBCL $1.5-5$ is known to have good reliability and validity. ${ }^{20,21}$ The raw scores on seven syndrome scales and five DSM-oriented scales are converted to normalized $\mathrm{T}$-scores $($ mean $=50$, standard deviation $=$ 10 ); we used scores on the internalizing, externalizing, aggressive behaviors, and total problems sections to evaluate the concurrent validity of the K-CSCB. The parents of school-aged children with ASD (aged 6-12 years) completed the CBCL 1.5-5. The CBCL 1.5-5 has been found to reliable in measuring problem behaviors in ASD youth over 5 years old. ${ }^{22}$

\section{Statistical analyses}

The demographic and clinical characteristics of the ASD and control groups were compared using independent t-tests for continuous variables and chi-square tests for categorical variables. In regard of missing data, the subscales scores of individuals that were missing more than 1 item were excluded from the analyses and only subscale scores that had not missing items were included. The reliability and validity analyses were based on the severity scores of each subscale. Cronbach's $\alpha$ was calculated to evaluate the internal consistency of the scale and each subscale. The test-retest reliability, correlation between subscales, and correlation between the frequency and severity score of each subscale were calculated using Pearson's correlation analyses. Concurrent validity was assessed using Pearson's correlation coefficients for scores on scales widely used for the assessment of problematic behavior, the BPI and CBCL. Discriminant validity was evaluated by comparing scores in the ASD and control groups via independent ttests. As there was a significant difference between the ASD and control groups in age and gender, we further compared the scores between the two groups using analysis of covariance (ANCOVA), with age and gender as covariates. To test the diagnostic utility and determine the cut-off score that best discriminates the ASD from the control group, we analyzed the receiver-operating-characteristic (ROC) curve and selected the score with the highest sensitivity and specificity.

All statistical analyses were performed using SPSS ver. 22.0 software (IBM Corp., Armonk, NY, USA), and statistical significance was set at a two-tailed $\mathrm{p}$-value $<0.05$.

\section{RESULTS}

The demographic characteristics of the ASD and control groups are shown in Table 1. We recruited 215 patients with ASD; demographic data were lacking for 1 , and 25 completed less than $95 \%$ of the K-CSCB. Of the 214 controls recruited, basic demographic data were lacking for 5 , and 41 completed less than half the K-CSCB. In total, data from 189

Table 1. Demographic characteristics of participants

\begin{tabular}{lccc}
\hline \multicolumn{1}{c}{ Characteristic } & ASD $(\mathrm{N}=189)$ & Control (N=168) & p-value \\
\hline Age (years), mean (SD) & $12.6(4.3)$ & $8.9(2.1)$ & $<0.001$ \\
Gender (male), N (\%) & $151(79.9)$ & & $<2(48.8)$ \\
Disability grade & & & \\
$\quad$ 1st & $103(55.1)$ & & \\
2nd & $62(33.2)$ & & \\
3rd & $2(1.1)$ & $108(65.5)$ & 0.966 \\
None & $20(10.7)$ & $100(72.5)$ & 0.027 \\
Annual family income $\geq \$ 2500, \mathrm{~N}(\%)$ & $121(65.1)$ & $122(76.7)$ & 0.787 \\
Paternal education $\geq$ college education, N (\%) & $145(82.9)$ & & \\
Maternal education $\geq$ college education, N (\%) & $138(78.0)$ & & \\
\hline
\end{tabular}

ASD: autism spectrum disorder, SD: standard deviation 
Table 2. Local prevalence of each item: ASD group

\begin{tabular}{|c|c|}
\hline Item & $\begin{array}{l}\text { Local prevalence } \\
\text { in } \operatorname{ASD}(\%)\end{array}$ \\
\hline Self-harm & 65.2 \\
\hline Biting & 24.1 \\
\hline Hitting with fist & 41.3 \\
\hline Hitting with an object & 21.2 \\
\hline Scratching & 36.0 \\
\hline Pinching & 9.5 \\
\hline Pulling body parts (hair, eyelashes, or nails) & 15.3 \\
\hline $\begin{array}{l}\text { Pulling body parts (e.g., eyeballs, tongue, } \\
\text { genitalia) }\end{array}$ & 3.2 \\
\hline Aggression & 56.5 \\
\hline Hitting & 31.2 \\
\hline Kicking & 9.0 \\
\hline Pushing & 26.1 \\
\hline Biting & 13.2 \\
\hline Pulling & 13.8 \\
\hline Scratching & 14.4 \\
\hline Pinching & 19.0 \\
\hline Throwing objects & 19.8 \\
\hline Abusing animals & 4.8 \\
\hline Stereotypy & 94.2 \\
\hline Rocking head & 31.1 \\
\hline Kicking the ground & 50.3 \\
\hline Rocking the body & 42.6 \\
\hline Smelling objects at close distances & 49.5 \\
\hline Moving body parts in circles & 37.0 \\
\hline Waving arms in air & 38.0 \\
\hline Going in circles & 30.9 \\
\hline Waving objects in circles & 22.2 \\
\hline Repeatedly moving fingers & 53.5 \\
\hline $\begin{array}{l}\text { Pursuing tactile stimuli (e.g., stickers, } \\
\text { toothpaste, bubble wrap) }\end{array}$ & 28.6 \\
\hline Smelling personal odor & 29.8 \\
\hline Repeatedly using objects in a specific pattern & 46.5 \\
\hline Rubbing oneself & 33.9 \\
\hline Staring at hands or objects & 43.9 \\
\hline Adopting an unusual posture & 18.2 \\
\hline Clapping hands & 32.4 \\
\hline Grimacing & 43.9 \\
\hline Open and closing zipper or buttons & 34.4 \\
\hline $\begin{array}{l}\text { Preferring specific shapes (e.g., circles, } \\
\text { straws, cable wires) }\end{array}$ & 34.0 \\
\hline Walking back and forth & 42.3 \\
\hline Staring into space & 36.0 \\
\hline Tapping objects & 38.3 \\
\hline Unresponsiveness/negativism & 88.0 \\
\hline Absence of play & 50.3 \\
\hline
\end{tabular}

Table 2. Local prevalence of each item: ASD group (continued)

\begin{tabular}{|c|c|}
\hline Item & $\begin{array}{l}\text { Local prevalence } \\
\text { in ASD }(\%)\end{array}$ \\
\hline Absence of verbal or nonverbal interactions & 49.5 \\
\hline Absence of response to physical contact & 18.2 \\
\hline $\begin{array}{l}\text { Absence of response to structured activities } \\
\text { (school activities, getting food at cafeteria) }\end{array}$ & 23.7 \\
\hline Difficulty reading facial emotions & 47.8 \\
\hline Absence of social reactions & 49.5 \\
\hline Too little or too slow motion & 31.6 \\
\hline $\begin{array}{l}\text { Absence of response to auditory stimuli } \\
\text { (name calling) }\end{array}$ & 47.9 \\
\hline $\begin{array}{l}\text { Staring at someone or something without } \\
\text { doing anything else }\end{array}$ & 41.6 \\
\hline Isolating from others & 54.8 \\
\hline Hiding in a small space & 24.9 \\
\hline Absence of response to verbal instructions & 39.4 \\
\hline Failure to care for hair or nails & 33.3 \\
\hline Attention deficit/hyperactivity & 94.3 \\
\hline Overly active & 63.8 \\
\hline Unable to stay still & 62.4 \\
\hline Interrupting activities & 30.7 \\
\hline Running around classroom & 48.7 \\
\hline Fidgeting & 28.9 \\
\hline Becoming easily excited & 67.6 \\
\hline Not paying attention to others' instructions & 70.8 \\
\hline Becoming easily distracted & 73.1 \\
\hline Disorganization & 73.1 \\
\hline Short attention span & 84.7 \\
\hline Breaking or losing belongings & 40.7 \\
\hline $\begin{array}{l}\text { Jumping from high places or running } \\
\text { into streets }\end{array}$ & 19.6 \\
\hline Inappropriate words or behavior & 96.4 \\
\hline Screaming inappropriately & 51.4 \\
\hline Temper tantrums & 53.0 \\
\hline Easily irritable & 51.9 \\
\hline $\begin{array}{l}\text { Overly sensitive to auditory stimuli } \\
\text { (e.g., firecrackers, speaker sound, echoing } \\
\text { sound of auditorium) }\end{array}$ & 62.0 \\
\hline Talking to oneself & 66.1 \\
\hline Repeating words or phrases & 68.3 \\
\hline Talking too loud or too much & 42.3 \\
\hline Humming or singing the same tune & 42.3 \\
\hline Uttering inappropriate sexual phrases & 13.2 \\
\hline Following others' words & 52.2 \\
\hline $\begin{array}{l}\text { Carrying around unusual objects } \\
\text { (e.g., fliers) }\end{array}$ & 21.9 \\
\hline $\begin{array}{l}\text { Exhibiting inappropriate sexual behavior } \\
\text { in public places }\end{array}$ & 23.8 \\
\hline
\end{tabular}

ASD: autism spectrum disorder 
patients with ASD and 168 controls were included in the analyses. The mean age was significantly higher and there were more male participants in the ASD than in the control group. Among the patients with ASD, $89.3 \%$ had a nationally registered disability grade, and $55.1 \%$ had the highest grade (grade 1 ), whereas only $1.1 \%$ had the lowest grade (grade 3 ).

The local prevalence of each item in the ASD population is presented in Table 2. All patients with ASD reported at least one problem behavior, and the subscale showing the highest prevalence was "inappropriate words or behavior" (96.4\%, ranging from $13.2 \%$ to $68.3 \%$ ), followed by attention deficit/hyperactivity (94.3\%) and stereotypy (94.2\%). The item with the highest prevalence was "short attention span" (84.7\%), and the item with the lowest prevalence was "pulling body parts (eyeballs, tongue, genitalia, etc.)" (3.2\%).

The internal consistency of the items was calculated, and six items from the self-harm category and eight items from the aggressive behavior category were deleted due to low item-total correlation (less than 0.3). As a result, the full-scale Cronbach's a was 0.97 , and all subscales showed fair internal consistency, ranging from 0.73 to 0.93 (Table 3). We found significant correlations between the frequency and the severity scores of

Table 3. Internal consistency, test-retest reliability, and frequencyseverity correlation of K-CSCB subscales

\begin{tabular}{lccc}
\hline \multicolumn{1}{c}{ Subscale } & Cronbach's alpha & Test-retest & F-S \\
\hline Self-harm & 0.73 & 0.26 & $0.95^{* *}$ \\
Aggressiveness & 0.80 & $0.40^{*}$ & $0.93^{* *}$ \\
Stereotypy & 0.93 & $0.49^{* *}$ & $0.96^{* *}$ \\
$\begin{array}{l}\text { Unresponsiveness/ } \\
\text { negativism }\end{array}$ & 0.92 & $0.51^{* *}$ & $0.63^{* *}$ \\
$\begin{array}{l}\text { Attention deficit/ } \\
\text { hyperactivity }\end{array}$ & 0.92 & $0.53^{* *}$ & $0.62^{* *}$ \\
$\begin{array}{l}\text { Inappropriate words } \\
\text { and behavior }\end{array}$ & 0.87 & $0.38^{*}$ & $1.00^{* *}$ \\
Total & & & \\
\hline
\end{tabular}

${ }^{*} \mathrm{p}<0.05,{ }^{* *} \mathrm{p}<0.01 . \mathrm{K}-\mathrm{CSCB}$ : Korean Comprehensive Scale for the Assessment of Challenging Behavior in Developmental Disorders, F-S: frequency-severity correlation each subscale. Thirty-two participants completed the retest after an interval of 4 weeks, and all subscales except that addressing self-harm showed statistically significant test-retest reliability $(\mathrm{p}<0.05)$ (Table 3$)$. There were significant correlations between each pair of subscales $(\mathrm{p}<0.01)$ (Table 4$)$.

The K-CSCB total and subscale scores were significantly higher in the ASD than in the control group $(\mathrm{p}<0.001)$ (Table 5 ). Even after including age and gender as covariates, all results remained significant $(\mathrm{p}<0.001)$.

The corresponding subscales of the K-CSCB were significantly correlated with the BPI scales addressing self-injury, stereotypic behaviors, and aggressive/destructive behaviors, and the total K-CSCB score was correlated with the total BPI score (Table 6). All K-CSCB subscales, except inappropriate words and behaviors and unresponsiveness, were significantly correlated with the corresponding CBCL subscales for internalizing, externalizing, aggressive behavior, and total behavior scores. The unresponsiveness scores showed significant correlation with internalizing and total CBCL scores.

According to the ROC analysis, the diagnostic utility of the full instrument was significant at $97.7 \%(\mathrm{p}<0.001)$, and the diagnostic utility of each subscale was also significant (Table 7). The cut-off score of the full instrument with the highest sensi-

Table 5. Comparison of the K-CSCB subscales score of ASD and control participants

\begin{tabular}{lrrr}
\hline \multicolumn{1}{c}{ Subscale } & $\begin{array}{c}\text { ASD } \\
(\mathrm{N}=189)\end{array}$ & $\begin{array}{c}\text { Control } \\
(\mathrm{N}=166)\end{array}$ & p-value \\
\hline Self-harm & $2.3(2.9)$ & $0.2(0.4)$ & $<0.001$ \\
Aggressiveness & $2.0(2.9)$ & $0.2(0.8)$ & $<0.001$ \\
Stereotypy & $11.7(9.9)$ & $0.6(1.3)$ & $<0.001$ \\
Unresponsiveness/negativism & $7.9(7.3)$ & $0.3(0.8)$ & $<0.001$ \\
Attention deficit/hyperactivity & $11.0(7.0)$ & $1.5(3.0)$ & $<0.001$ \\
Inappropriate words and & $8.8(5.7)$ & $0.7(1.5)$ & $<0.001$ \\
$\quad$ behavior & & & \\
Total & $41.6(25.2)$ & $3.3(5.0)$ & $<0.001$ \\
\hline
\end{tabular}

K-CSCB: Korean Comprehensive Scale for the Assessment of Challenging Behavior in Developmental Disorders, ASD: autism spectrum disorder

Table 4. Correlation between subscales of the K-CSCB

\begin{tabular}{|c|c|c|c|c|c|c|}
\hline Subscale & Self-harm & Aggressiveness & Stereotypy & $\begin{array}{l}\text { Unresponsiveness/ } \\
\text { Negativism }\end{array}$ & $\begin{array}{l}\text { Attention deficit/ } \\
\text { hyperactivity }\end{array}$ & $\begin{array}{c}\text { Inappropriate } \\
\text { words and } \\
\text { behavior }\end{array}$ \\
\hline Self-harm & 1.00 & & & & & \\
\hline Aggressiveness & $0.45^{*}$ & 1.00 & & & & \\
\hline Stereotypy & $0.68^{*}$ & $0.46^{*}$ & 1.00 & & & \\
\hline Unresponsiveness/ negativism & $0.40^{*}$ & $0.31^{*}$ & $0.54^{*}$ & 1.00 & & \\
\hline Attention deficit/ hyperactivity & $0.44^{*}$ & $0.38^{*}$ & $0.58^{*}$ & $0.81^{*}$ & 1.00 & \\
\hline Inappropriate words and behavior & $0.42^{*}$ & $0.30^{*}$ & $0.57^{*}$ & $0.75^{*}$ & $0.83^{*}$ & 1.00 \\
\hline
\end{tabular}

${ }^{*} \mathrm{p}<0.01$. K-CSCB: Korean Comprehensive Scale for the Assessment of Challenging Behavior in Developmental Disorders 
Table 6. Correlation of K-CSCB subscales with BPI and CBCL subscales

\begin{tabular}{|c|c|c|c|c|c|c|c|c|}
\hline \multirow[b]{2}{*}{ Subscales } & \multicolumn{4}{|c|}{ BPI } & \multicolumn{4}{|c|}{ CBCL } \\
\hline & Self-injury & $\begin{array}{c}\text { Stereotyped } \\
\text { behavior }\end{array}$ & $\begin{array}{l}\text { Aggression/ } \\
\text { destruction }\end{array}$ & Total & Externalizing & Internalizing & Aggressiveness & Total \\
\hline Self-harm & $0.753^{* *}$ & $0.612^{* *}$ & $0.422^{* *}$ & $0.704^{* *}$ & $0.242^{*}$ & $0.262^{*}$ & $0.277^{*}$ & $0.300^{* *}$ \\
\hline Aggressive & $0.502^{* *}$ & $0.415^{* *}$ & $0.811^{* *}$ & $0.556^{* *}$ & $0.626^{* *}$ & $0.422^{* *}$ & $0.683^{* *}$ & $0.501^{* *}$ \\
\hline Stereotypy & $0.688^{* *}$ & $0.924^{* *}$ & $0.456^{* *}$ & $0.916^{* *}$ & $0.487^{* *}$ & $0.669^{* *}$ & $0.430^{* *}$ & $0.654^{* *}$ \\
\hline Unresponsiveness & $0.435^{* *}$ & $0.502^{* *}$ & $0.306^{* *}$ & $0.528^{* *}$ & 0.224 & $0.244^{*}$ & 0.222 & $0.262^{*}$ \\
\hline $\begin{array}{l}\text { Attention deficit/ } \\
\text { hyperactivity }\end{array}$ & $0.466^{* *}$ & $0.503^{* *}$ & $0.361^{* *}$ & $0.537^{* *}$ & $0.329^{* *}$ & $0.348^{* *}$ & $0.298^{* *}$ & $0.358^{* *}$ \\
\hline $\begin{array}{l}\text { Inappropriate words } \\
\text { and behavior }\end{array}$ & $0.429^{* *}$ & $0.513^{* *}$ & $0.289^{* *}$ & $0.522^{* *}$ & 0.049 & 0.133 & 0.059 & 0.103 \\
\hline Total & $0.613^{* *}$ & $0.739^{* *}$ & $0.460^{* *}$ & $0.769^{* *}$ & $0.468^{* *}$ & $0.619^{* *}$ & $0.428^{* *}$ & $0.594^{* *}$ \\
\hline
\end{tabular}

${ }^{*} \mathrm{p}<0.05,{ }^{* *} \mathrm{p}<0.01 . \mathrm{K}-\mathrm{CSCB}$ : Korean Comprehensive Scale for the Assessment of Challenging Behavior in Developmental Disorders, BPI: Behavior Problems Inventory, CBCL: Child Behavior Checklist

Table 7. Area under ROC curve for each subscale

\begin{tabular}{lcc}
\hline \multicolumn{1}{c}{ Subscale } & AUC & SE \\
\hline Self-harm & $0.778^{*}$ & 0.030 \\
Aggressiveness & $0.733^{*}$ & 0.032 \\
Stereotypy & $0.933^{*}$ & 0.016 \\
Unresponsiveness/negativism & $0.904^{*}$ & 0.020 \\
Attention deficit/hyperactivity & $0.897^{*}$ & 0.020 \\
Inappropriate words and behavior & $0.946^{*}$ & 0.014 \\
Total & $0.977^{*}$ & 0.007 \\
\hline
\end{tabular}

${ }^{*} \mathrm{p}<0.001$. ROC: receiver operating characteristic, AUC: area under curve, SE: standard error

tivity and specificity was 12.5 points. At this score, the sensitivity was $90.4 \%$, the specificity was $94.7 \%$, the positive-predictive value was $93.4 \%$, and the negative-predictive value was $92.2 \%$.

\section{DISCUSSION}

The K-CSCB is the first tool developed in Korean designed to evaluate behavioral problems in ASD. It is the only instrument that includes such important items as "repeatedly opens and closes zippers or buttons on clothes," "repeatedly pursues a particular tactile sensation (e.g., stickers, toothpaste, bubble wrap)," and "overly sensitive to auditory sensations (e.g., echoing sound of auditorium, firecrackers, speaker noise)." All of these items showed a high local prevalence in the ASD population (34.4, 28.6, and 62.0\%, respectively). Another strength of this study is that we recruited participants from both clinics and special education schools. As interventions for problematic behavior can be applied not only in the clinical setting (e.g., pharmacotherapy) but also in the school setting (e.g., behavioral therapy), it is important that this instrument was validated in populations from both settings.
This study provides evidence that the K-CSCB is valid and reliable. It showed excellent internal consistency (Cronbach's $\alpha=0.97$ ), which exceeded those of the previous aforementioned instruments (BPI $=0.83, \mathrm{ABC}=0.68-0.90$, HSQ-PDD $=$ 0.80 and 0.90 , CBCL $1.5-50.93){ }^{11,14,21,23}$ The test-retest reliability was significant for most subscales; the only exceptions, the self-harm subscale, may be attributable to the small number of participants who completed the retest, causing increased probability of type II errors. Moreover, as self-harm behavior requires more immediate intervention compared to other behaviors, the stability of this construct could vary over time. Further studies with a larger sample size are needed to confirm the test-retest reliability of the K-CSCB. The K-CSCB also showed good discriminant validity and concurrent validity, especially with the BPI $(r=0.77)$.

Whereas most scales measure only the severity of a problem behavior, the K-CSCB simultaneously measures severity and frequency. This may be useful in clinical situations where the severity and frequency of a problem behavior do not match, as a severe problem may be infrequent or a frequent problem may not be severe. However, as the frequency and severity scales showed a strong correlation with each other, little may be gained from retaining both scales, and it may be possible to eliminate one of them. We suggest the flexible use of both scales according to the purpose of data collection.

Total scores on the K-CSCB range from 0 to 225; in the ASD population in our study, the lowest score was 3 and the highest score was 120. All participants in this group reported more than one problematic behavior, which is a higher rate than found in previous studies. A study using the BPI found that three-quarters of the sample endorsed at least one item; the highest prevalence rate among items was $22.2 \%,{ }^{11}$ whereas the highest in this study was $84.8 \%$. The high prevalence of problem behaviors in this study may have been due to the fact that 
the ASD population was over-represented by individuals with high severity, as more than half had a disability grade of 1 (highest grade). However, comparison with the results of other studies may be difficult due to differences in study populations, sampling strategies, and study designs. As the prevalence of problematic behavior among patients with ASD has not been studied in South Korea, the K-CSCB could be a valuable tool in future epidemiological research.

Kalb and Loeber reported that $25 \%$ to $65 \%$ of children aged 2-16 years of age have problems with noncompliance. ${ }^{24}$ Among children with autism, compliance with instructions may be particularly important because of the many requests to comply with adult directions that are issued during early behavioral interventions. ${ }^{25}$ Despite the high rate of noncompliance in patients with ASD, the HSQ-PDD is the only accepted tool that measures behavioral non-compliance in children with ASD. ${ }^{14}$ Although the items are not as specific as those in the HSQ-PDD, some of the items on the "unresponsiveness/negativism" subscale of the K-CSCB may reflect non-compliance in patients with $\operatorname{ASD}$ (e.g., no response to verbal instruction, no response to structured activities). As the BPI and CBCL do not measure noncompliance per se, further research investigating concurrent validity with HSQ-PDD are needed.

ASD is associated with high rates of comorbidity with attention-deficit/hyperactivity disorder (ADHD), and 30-80\% of those with ASD meet the criteria for ADHD.$^{25}$ Owing to the overlapping characteristics and etiological factors, Rommelse has convincingly argued that the two disorders should be systematically studied together. ${ }^{26,27}$ There was also a high rate of $\mathrm{ADHD}$ traits in the ASD population in this study. The most prevalent item was "short attention span," and $94.3 \%$ of the children with ASD had affirmative responses to at least one item in the "attention deficit/hyperactivity" subscale. Thus, we propose that the K-CSCB may have a promising role in future research involving comorbid ASD and ADHD.

There were some noteworthy limitations to this study. First, although the patients with ASD recruited by hospitals were diagnosed by child and adolescent psychiatrists, we relied on parent reports for confirmation of the ASD diagnosis of the participants recruited by special education schools. There was also a significant difference between the ASD and control groups in age and gender. We tried to compensate for this by adding age and gender as covariates, and this did not alter the significance of the results. We used the CBCL $1.5-5$ version in school-aged ASD children. However, as the developmental age of ASD children are lower compared to typically developed children, the use of the CBCL 1.5-5 in ASD may capture the behavioral problems in school-age ASD individuals well. Finally, the participants consisted primarily of children and adolescents, which limits the generalizability of our findings to adults with ASD.

The K-CSCB is a new tool for the assessment of problem behavior in patients with ASD, and this study provides evidence for its validity and reliability. As this is the first tool in Korean, we expect that this tool will be widely used in clinical and research settings in South Korea.

\section{Supplementary Materials}

The online-only Data Supplement is available with this article at https://doi.org/10.4306/pi.2018.15.1.54.

\section{Acknowledgments}

This work was supported by a grant of the Korean Social Service R\&D Project, Ministry of Health and Welfare, Republic of Korea (HI14C1098).

\section{REFERENCES}

1. Baird G, Simonoff E, Pickles A, Chandler S, Loucas T, Meldrum D, et al. Prevalence of disorders of the autism spectrum in a population cohort of children in South Thames: the Special Needs and Autism Project (SNAP). Lancet 2006;368:210-215.

2. Fombonne E. The epidemiology of autism: a review. Psychol Med 1999; 29:769-786.

3. Fombonne E. Epidemiology of pervasive developmental disorders. Pediatr Res 2009;65:591-598.

4. Kim YS, Leventhal BL, Koh YJ, Fombonne E, Laska E, Lim EC, et al. Prevalence of autism spectrum disorders in a total population sample. Am J Psychiatry 2011;168:904-912.

5. American Psychiatric Association. Diagnostic and Statistical Manual of Mental Disorders (5th Ed). Washington, DC: American Psychiatric Association; 2013.

6. Horner RH, Carr EG, Strain PS, Todd AW, Reed HK. Problem behavior interventions for young children with autism: a research synthesis. J Autism Dev Disord 2002;32:423-446.

7. Luiselli JK, Blew P, Keane J, Thibadeau S, Holzman T. Pharmacotherapy for severe aggression in a child with autism: "open label" evaluation of multiple medications on response frequency and intensity of behavioral intervention. J Behav Ther Exp Psychiatry 2000;31:219-230.

8. Hartley SL, Sikora DM, McCoy R. Prevalence and risk factors of maladaptive behaviour in young children with Autistic Disorder. J Intellect Disabil Res 2008;52:819-829.

9. Gadow KD, DeVincent CJ, Pomeroy J, Azizian A. Psychiatric symptoms in preschool children with PDD and clinic and comparison samples. J Autism Dev Disord 2004;34:379-393.

10. Aman MG, Singh N. Aberrant Behavior Checklist Manual. East Aurora, New York: Slosson Educational Publications; 1986.

11. Rojahn J, Matson JL, Lott D, Esbensen AJ, Smalls Y. The Behavior Problems Inventory: an instrument for the assessment of self-injury, stereotyped behavior, and aggression/destruction in individuals with developmental disabilities. J Autism Dev Disord 2001;31:577-588.

12. Aman MG, Tasse MJ, Rojahn J, Hammer D. The Nisonger CBRF: a child behavior rating form for children with developmental disabilities. Res Dev Disabil 1996;17:41-57.

13. Kamphaus R, Reynolds C. BASC-2 behavioral and emotional screening system manual. Circle Pines, MN: Pearson; 2007.

14. Chowdhury M, Aman MG, Scahill L, Swiezy N, Arnold LE, Lecavalier L, et al. The Home Situations Questionnaire-PDD version: factor structure and psychometric properties. J Intellect Disabil Res 2010;54:281291.

15. Achenback TM, Rescorla L. Manual for ASEBA preschool forms and profiles. Burlington, Bermont: Research Center for Children, Youth and Families, University of Vermont; 2000. 
16. Hanratty J, Livingstone N, Robalino S, Terwee CB, Glod M, Oono IP, et al. Systematic review of the measurement properties of tools used to measure behaviour problems in young children with autism. PLoS One 2015;10:e144649.

17. Chowdhury M, Aman MG, Lecavalier L, Smith T, Johnson C, Swiezy $\mathrm{N}$, et al. Factor structure and psychometric properties of the revised Home Situations Questionnaire for autism spectrum disorder: The Home Situations Questionnaire-Autism Spectrum Disorder. Autism 2016;20:528-537.

18. Oh KJ, Lee H, Hong KE, Ha EH. K-CBCL. Seoul: Chung Ang Aptitute Publishing Co; 1997.

19. Ahn CM, Ebesutani C, Kamphaus R. A psychometric analysis and standardization of the Behavior Assessment System for Children-2, SelfReport of Personality, Child Version among a Korean sample. Sch Psychol Q 2014;29:198-212.

20. Achenback TM, Rescorla L. Manual for the ASEBA Preschool Forms and Profiles: A Integrated System of Multi-Informant Assessment. Burlington, VT: University of Vermont, Deparment of Psychiatry; 2001.

21. Pandolfi V, Magyar CI, Dill CA. Confirmatory factor analysis of the Child Behavior Checklist 1.5-5 in a sample of children with autism spectrum disorders. J Autism Dev Disord 2009;39:986-995.
22. Baseten B, van der Ende J, Tiemeier H, Althoff RR, Jolien R, Jaddoe VW, et al. Nonverbal intelligence in young children with dysregulation: the Generation R Study. Eur Child Adolesc Psychiatry 2014;23: 1061-1070.

23. Karabekiroglu K, Aman MG. Validity of the aberrant behavior checklist in a clinical sample of toddlers. Child Psychiatry Hum Dev 2009;40: 99-110.

24. Kalb LM, Loeber R. Child disobedience and noncompliance: a review. Pediatrics 2003;111:641-652.

25. Fischetti AT, Wilder DA, Myers K, Leon-Enriquez Y, Sinn S, Rodriguez R. An evaluation of evidence-based interventions to increase compliance among children with autism. J Appl Behav Anal 2012;45:859-863.

26. Rommelse NN, Geurts HM, Franke B, Buitelaar JK, Hartman CA. A review on cognitive and brain endophenotypes that may be common in autism spectrum disorder and attention-deficit/hyperactivity disorder and facilitate the search for pleiotropic genes. Neurosci Biobehav Rev 2011;35:1363-1396.

27. Rommelse NN, Altink ME, Fliers EA, Martin NC, Buschgens CJ, Hartman CA, et al. Comorbid problems in ADHD: degree of association, shared endophenotypes, and formation of distinct subtypes. Implications for a future DSM. J Abnorm Child Psychol 2009;37:793-804. 